\title{
THEORETICAL NOUS IN THE POSTERIOR ANALYTICS
}

\author{
BENJAMIM MORISON \\ https:/ / orcid.org/0000-0002-6574-8058 \\ Princeton University \\ Department of Philosophy \\ Princeton, New Jersey \\ United States \\ bmorison@princeton.edu
}

\section{Article info \\ CDD: 185}

Received: 16.10.2019; Accepted: 18.10.2019

DOI: http://dx.doi.org/10.1590/0100-6045.2019.V42N4.BM

\author{
Keywords \\ Aristotle \\ Knowledge \\ Understanding \\ Episteme \\ Nous
}

\begin{abstract}
According to Aristotle's definition of episteme (understanding) in the Posterior Analytics, you have episteme of the proposition that $\mathrm{P}$ when you know why $\mathrm{P}$, and you know that it is necessary that P. Episteme is therefore only available for propositions which have an explanation, i.e. the theorems of the science. It is a demanding cognitive state, since knowing the explanation of a proposition in a science requires being able to demonstrate or prove it. Aristotle occasionally refers to the counterpart notion to episteme which applies to propositions which lack an explanation, i.e. the first principles of a science. This counterpart notion is nous, or non-demonstrative understanding. Aristotle never defines it, but it should turn out to be an equally demanding cognitive state to achieve. This paper proposes that you have nous of the proposition that $\mathrm{P}$ when you know that nothing explains why $\mathrm{P}$, you know the various ways in which the proposition that $\mathrm{P}$ features in explanations in the science, and you know that it is necessary that $P$.
\end{abstract}




\section{\$1 INTRODUCTION TO EPISTEME}

Nous, sometimes translated 'insight' or 'intuition', is an indispensable part of Aristotle's epistemological scheme in the Posterior Analytics. When Jonathan Barnes wrote that "Nous has no importance" in that work, ${ }^{1}$ he did not mean to deny this, but only to record the undeniable fact that, despite its importance to the overall picture Aristotle develops, Aristotle says surprisingly little about it, and in particular, offers no definition of it. In this paper, I intend to offer just such a definition, a defence of that definition, and some reflections on its interest as a philosophical notion.

'Nous' is a term which appears often in Aristotle, in different contexts and with different meanings. The goal of this paper is to understand Aristotle's notion of nous in the Posterior Analytics. Since the Posterior Analytics is about scientific knowledge, which is the kind of knowledge appropriate for scientific or theoretical domains such as mathematics, physics, or metaphysics, one could think of nous in that work as being theoretical, insofar as it is of truths in those theoretical domains. (Thus one could compare nous in the Posterior Analytics with its distinctively practical counterpart in Nicomachean Ethics VI, where Aristotle introduces a kind of nous which is of truths in practical domains. $\left.{ }^{2}\right)$

To understand nous in the Posterior Analytics, we must first rehearse Aristotle's account of episteme. My summary will

\footnotetext{
1 Jonathan Barnes, Aristotle: Posterior Analytics (Clarendon Aristotle Series; second edition, Oxford, 1994), 270.

${ }^{2}$ For a detailed comparison, see Benjamin Morison, 'Practical Nous in the Nicomachean Ethics', OS AP LVII, Winter 2019, 219-47.
} 
hold nothing new. ${ }^{3}$ The place to start is Posterior Analytics I 2, 71b9-12, when Aristotle defines what it is to understand something:

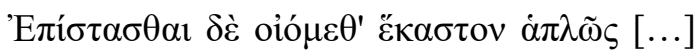

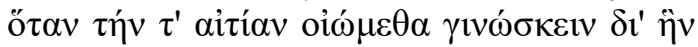

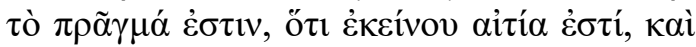

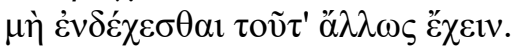

We think we understand something simpliciter $[\ldots]$ when we think we know of the explanation because of which the object holds that it is its explanation, and also [when we think we know] that it is not possible for it to be otherwise. ${ }^{4}$

This definition tells us that understanding something, for Aristotle, consists in knowing not only that it is the case, but also why it is the case: it is this feature of episteme which led Myles Burnyeat to insist that what Aristotle is defining here is not the ordinary everyday knowledge that we all have in virtue of being rational beings going about our business in the world, but rather the more cognitively demanding state

${ }^{3}$ It agrees in broad outline with e.g. Myles Burnyeat, 'Aristotle on Understanding Knowledge', in E. Berti (ed.), Aristotle on Science: The Posterior Analytics (Padua, 1981), 97-139; David Bronstein, Aristotle on Knowledge and Learning: The Posterior Analytics (Oxford, 2016); and in particular Hendrik Lorenz ('Understanding, Knowledge, and Enquiry in Aristotle', in F. Sheffield and J. Warren (eds.), Routledge Companion to Ancient Pbilosophy (London, 2013), 290-303.

${ }^{4}$ Translations from the Posterior Analytics are taken from Barnes 1994, unless otherwise indicated. The addition in this passage is mine, for clarity. 
of understanding. ${ }^{5}$ Aristotle's account of episteme is an account of the epistemic state of the expert, a state which is far from quotidian, and rather difficult to obtain. For instance, to have understanding of Pythagoras' theorem, that in a right-angled triangle, the square on the hypotenuse equals the sum of the squares on the two opposing sides, one is required to know why this geometrical fact holds. For Aristotle, knowing that explanation will take the form of being able to trace the proof of the theorem back to the geometrical first principles operative in the domain of plane geometry.

Understanding that $\mathrm{P}$ consists in knowing why $\mathrm{P}$. So unless there are self-explanatory facts, understanding that $\mathrm{P}$ will involve knowing of another fact that it is the explanation of why P. (There might be self-explanatory facts, of a sort, and they will be discussed later.) But assuming for the moment that there are not self-explanatory facts, understanding comes out as relational, and more specifically, 'other-involving': to have episteme that $\mathrm{P}$ is to know that $\mathrm{P}$ because $Q$, where the fact that $\mathrm{Q}$ (which might be a complex fact, or set of facts) is different from the fact that $P$.

If the first condition Aristotle puts on understanding that $\mathrm{P}$ is that one knows why $\mathrm{P}$, the second condition is that one knows that it is necessary that P. ${ }^{6}$ The target facts for episteme

5 In Burnyeat 1981; see also Myles Burnyeat, 'Episteme', in B. Morison and K. Ierodiakonou (eds.), Episteme etc.: Essays in Honour of Jonathan Barnes (Oxford, 2011), 3-29.

${ }^{6}$ Here, I am assuming that the referent of the word ' $\tau$ oṽ $\tau$ ' at $71 \mathrm{~b} 15$ is the proposition of which we are to have episteme. Other scholars have developed an alternative interpretation according to which the word refers to the explanatory connection mentioned in the first clause, and hence that Aristotle is saying that it is that connection which is necessary. See for instance Lucas Angioni, 'Aristotle's Definition of Scientific Knowledge', in P. S. Hasper and K. Ierodiakonou (eds.), Logical Analysis and History of Pbilosopby 19: Ancient Epistemology (Münster, 2016), 140-66.

Manuscrito - Rev. Int. Fil. Campinas, v. 42, n. 4, pp. 1-43, Oct-Dec. 2019. 
are therefore necessary truths, facts which are part of the unchanging structure of reality. Although he never says it, this is presumably why Aristotle's favoured vehicle for manifesting the explanatory relations that need to be grasped by a person with episteme is a syllogism meeting various conditions (such a syllogism is a demonstration). In a syllogism, the truth of the premisses necessitates the truth of the conclusion; thus, if you start with necessary truths as your premisses, you are guaranteed to end up with necessary truths as your conclusions. That means that syllogisms are an appropriate vehicle for capturing relations between necessary truths. Demonstrations are then defined as those syllogisms mastery of which will confer episteme of their conclusion, ${ }^{7}$ i.e. those syllogisms where the necessary truths which comprise their premisses will explain (and not just necessitate) their conclusion.

Aristotelian syllogisms paradigmatically consist of two premisses and a conclusion, but of course not every necessary truth is explained by precisely two facts. Aristotle thus allows that demonstrations can be complex, where the conclusion of one syllogism becomes a premiss of another, so as to form a chain of syllogisms whose ultimate conclusion is the fact to be explained. In this, he is clearly in line with the scientific practice of ancient geometers such as Euclid. ${ }^{8}$ For instance, in the proof of Pythagoras' theorem (Elements I 47), Euclid calls upon several earlier theorems, and makes use of them as premisses, including the directly

7 Post. An. I 2, 71b17-18.

${ }^{8}$ I say this without taking a stance here on the question of mutual influence. For more on this, see Jonathan Barnes, 'Aristotle's Theory of Demonstration', Phronesis 14 (1969), 123-152, reprinted in his Proof, Knowledge, and Scepticism: Essays in Ancient Philosophy III (Oxford, 2014), 129-57. 
preceding one, I $46 .{ }^{9}$ So from a set of first principles, one might deduce some theorems; these theorems can in turn be used as premisses of further deductions whose conclusions will also be theorems, even though those deductions did not have first principles as premisses. A demonstration of a proposition will be a tree of syllogisms tracing back the derivation of the target proposition from first principles, through the appropriate explanatory propositions. ${ }^{10}$

\section{\$2 REGRESSES LOOM AND ARE SOLVED BY INTRODUCING DIFFERENT TYPES OF KNOWING}

Aristotle's definition of episteme derives from Plato's characterisation of episteme in the Meno, in which Plato has Socrates suggest that obtaining episteme that $\mathrm{P}$ is a matter of

\footnotetext{
${ }^{9}$ In fact, the immediately preceding result is a so-called problem, not a theorem, i.e. a new permission for construction. For the distinction between problems and theorems, and the difficulties these might pose for Aristotle's account of scientific understanding, see Beere and Morison (ms).

10 The full or complete demonstration of a proposition is the tracing back of its derivation all the way to first principles through the appropriate propositions; one might more loosely call a derivation a 'demonstration' if it uses as premisses previously proven theorems (as in the case of Euclid I 47: the derivation displayed there of Pythagoras' theorem contains some first principles as premisses and some previously proven theorems, and so it only loosely counts as a demonstration). For a more formal recursive definition of complete demonstration, see Jonathan Barnes, 'Proof and the Syllogism', in E. Berti (ed.), Aristotle on Science: the Posterior Analytics (Padua, 1981), 17-59, reprinted in his Proof, Knowledge, and Scepticism: Essays in Ancient Pbilosopby III (Oxford, 2014), 95-128, at 102 n.12 of the reprint.
} 
working out the explanation for why $\mathrm{P}$, i.e. to have episteme that $\mathrm{P}$ is to know why $\mathrm{P}$ :

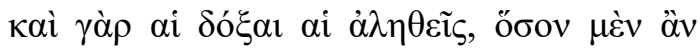

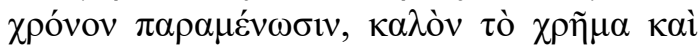

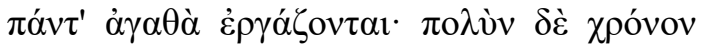

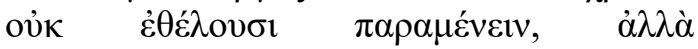

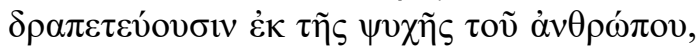

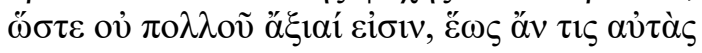

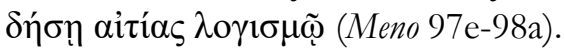

'For true opinions too are a fine thing as long as they stay in their place, and produce all sorts of good things; but they are not willing to stay in their place for a long time, but run away out of a man's soul, so they are not worth very much, until someone ties them down by working out the explanation.' [Trans. Sharples $\left.{ }^{11}\right]$

Plato's characterisation of episteme here is obviously very far from complete, and it is probably not intended to be complete. ${ }^{12}$ But it shares with Aristotle the 'other-involving' characterisation of episteme: having episteme of one proposition requires standing in another relation to another proposition (i.e. the proposition which is the explanation of the first proposition). But where we have an account which is in this way 'other-involving' the threat of regress looms. To have

${ }^{11}$ R. W. Sharples, Plato: Meno (London, 1985).

${ }^{12}$ Commentators work hard at extracting a definition of episteme from a text whose ostensible aim is merely to give some features which distinguish it from doxa; in the Meno, of all dialogues, we should be wary of conflating the mere features of something with its definition (71b). 
episteme that $\mathrm{P}$ is to know something about something else, namely the explanation of why $\mathrm{P}$, call it the group of propositions, Q, which jointly constitute that explanation (and which would feature on the right-hand side of a because-statement whose left-hand side was P). But what cognitive grasp are we supposed to have of those propositions that comprise Q? In the absence of being told anything else, we must assume it is episteme. But the characterisation of episteme tells us that if we are to have episteme of the propositions in Q, we must know why they hold, in other words we must know some propositions in addition to the propositions in $\mathrm{Q}$, namely the group of propositions $\mathrm{R}$ (which explain why the propositions in $\mathrm{Q}$ hold). And if our knowledge of $\mathrm{R}$ is episteme, we must know some propositions other than the proposition in $\mathrm{R}$, and so on. Plato's characterisation of episteme doesn't tell us how to solve this regress, if the regress needs solving.

But there is a second regress looming. If my episteme that $\mathrm{P}$ depends on me knowing that $\mathrm{P}$ because Q (for some suitable choice of ' $Q$ '), then we seem to have swapped knowledge of one proposition ('P') for another ('P because Q'). But what kind of knowledge do I have of 'P because Q'? If it is episteme, then I need to know why that proposition is true. That means working out the explanation of that proposition, i.e. knowing something of the form '((P because Q) because A)'. And if I am to have episteme of that, then I will need to know something of the form '( ((P because $Q)$ because A) because B)'. And so on. It's not clear that these propositions even make sense, but if we are to work out the explanation of the target proposition, aren't we supposed to come to know that explanation?

The first regress looms because our episteme that $P$ appears to require us to know something else, namely that $\mathrm{Q}$ (assuming that $\mathrm{P}$ because Q), and in the absence of being told about any other way of knowing a proposition, our grasp of the Q part seems to have to be episteme itself, thereby 
requiring us to know that $\mathrm{R}$ (assuming that $\mathrm{Q}$ because $\mathrm{R}$ ), etc. In the second regress, our episteme that $\mathrm{P}$ appears to require us to know the complex proposition 'P because Q', and in the absence of being told about any other way of knowing a proposition, our grasp of 'P because Q' seems to have to be episteme itself, thereby requiring us to know something of the form '( $\mathrm{P}$ because $\mathrm{Q})$ because R', etc.

The two regresses are different, as a rough and ready sketch of their logical form will show:

Regress 1:

To know that $P$, you have to know that:
(1) P because $Q$
(2) Q because $\mathrm{R}$
(3) $R$ because $S$
(4) Etc.

Regress 2:

To know that $P$, you have to know that:

(1) P because $Q$

(2) (P because Q) because X

(3) ( $($ P because $Q)$ because $\mathrm{X})$ because $\mathrm{Y})$

(4) etc.

Aristotle takes seriously both of these regresses. Recall his definition of understanding:

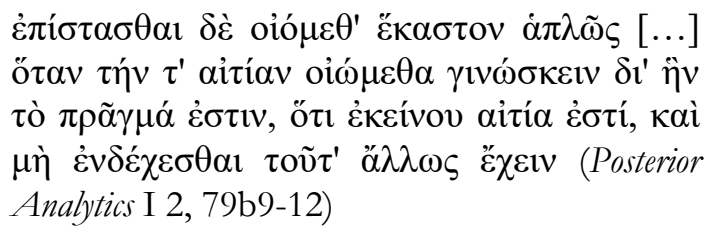


At first sight, the definition looks very similar to Plato's characterisation. You understand the fact that $\mathrm{P}$ when:

(i) You know why P;

(ii) You know that it is necessary that P.

Obviously, the idea that you have episteme of something when you know its explanation is very close to what Plato said in the Meno. The only addition seems to be clause (ii): that one must know that the proposition in question is necessary. However, Aristotle's definition offers some help with regress 2: in the very definition of episteme, when it is stated that one must know the explanation why $\mathrm{P}$ (i.e. one must know that P because Q), the verb for 'know'

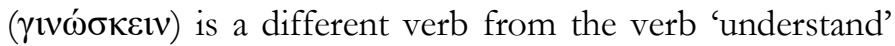

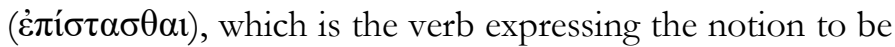
defined. And just as well, on pain of the definition being circular. In other words, in Aristotle's definition, it is clear that the kind of knowledge you are to have of the explanation why $\mathrm{P}$ is different from episteme.

This point is quite striking. Aristotle in effect is saying that we do not have episteme of because-statements. And this is borne out by the system he describes in the Posterior Analytics. For if we are to have episteme of $\mathrm{P}$, we must be able to demonstrate $\mathrm{P}$; that is, in the simplest case, produce a syllogism whose premisses are first principles of the system, and whose conclusion is the very proposition $\mathrm{P}$ of which we have episteme. ${ }^{13}$ No proposition of the form 'P because Q' features in this demonstration. Because-statements are not the conclusions of the demonstrations. The demonstration

13 For some suggestive remarks on this, see Lucas Angioni, 'Demonstração, Silogismo e Causalidade', in Lucas Angioni (ed.), Lógica e Ciência em Aristóteles (Campinas, 2014), 61-120, at 75-83. 
gives the materials of the explanation: the premisses are the explanantia, and the conclusion is the explanandum. The propositions of the science are arranged into demonstrations, which display why the conclusions are the case, but the demonstrations never use words like 'because', or 'explanation'. 14

So words for explanation do not feature in the propositions of the science. Moreover, causal vocabulary does not even feature when we are exhibiting the relationships between propositions of the science. The Aristotelian science will contain words to indicate that a conclusion is being drawn syllogistically, words such as 'therefore'. But syllogistic consequence, as Aristotle himself reminds us, ${ }^{15}$ is not sufficient for a demonstration. What makes a demonstration count as a demonstration is the combination of syllogistic consequence plus the various conditions that the premisses must meet (notably, being explanatory of the conclusion). ${ }^{16}$ Thus, the words indicating the relations between the propositions of the science are not causal locutions either.

14 See Bronstein 2016: 'The explanation is revealed over the demonstration as a whole' (38).

15 After giving the various conditions that the premisses of a demonstration have to meet, he tells us that 'there can be a deduction even if these conditions are not met, but there cannot

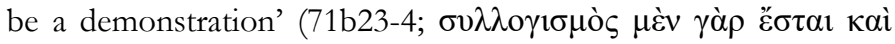

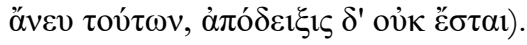

${ }^{16}$ It might be worth pointing out here that the condition that Aristotle places on mere syllogistic concludence, that the conclusion follow necessarily from the premisses 'because they are

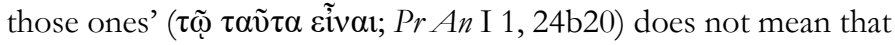
the truth of the conclusion (if is true) is explained by the premisses (if they are true): he means that the fact that the conclusion follows from the premisses must be explained by the choice of premisses. 
This matches actual scientific practice, if we take as our illustrative model a science such as geometry as laid out by Euclid in his Elements. Euclid is full of words indicating consequence, but precious little causal vocabulary. The propositions to be proved don't contain causal vocabulary, and Euclidean proofs are not signposted with causal vocabulary either. Even if the proof that Euclid offers of the construction of the equilateral triangle (Elements I 1) does in fact explain why the constructed figure is an equilateral triangle, there is no language in the proof to indicate any relation between the propositions other than the logical derivation of conclusions from the premisses (expressed by Euclid, apparently interchangeably, by words like $\dot{\varepsilon} \pi \varepsilon i ́$ and $\alpha \not \rho \alpha)$. Thus, a scientific treatise such as Euclid's Elements, if it thinks of itself as explaining truths, does so in the way envisaged by Aristotle, namely by presenting demonstrations without causal vocabulary.

Thus for Aristotle, the proposition 'P because Q' appears not to be one susceptible to episteme, i.e. knowing that $\mathrm{P}$ because $Q$ is not a matter of knowing a scientific proposition. Knowing that $\mathrm{P}$ because Q (for Aristotle) is a matter of seeing the explanatory relationship between the fact that P and the fact that Q; there isn't some fresh proposition 'P because Q' which needs to be investigated, proved, or laid down.

There is a parallel to be made with Aristotle's second clause for episteme, the clause that says that the person who

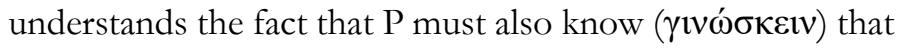
the proposition that $\mathrm{P}$ 'cannot be otherwise' (i.e. that it is necessary that P). ${ }^{17}$ Just as in the case of the explanation why

${ }^{17}$ In theory, one could take the clause 'that P cannot be otherwise' as in the scope of 'we think' rather than 'we think we know'. But this is not very likely, especially in the light of $75 \mathrm{a} 14$ (see Barnes 1994, 90). 
$\mathrm{P}$ that we are supposed to know if we are to have episteme that $\mathrm{P}$, so the modal status of the proposition that $\mathrm{P}$ as a necessary truth is something we are supposed to know if we are to have episteme that P. But the propositions in the science do not themselves get expressed with modal operators ${ }^{18}$. So the necessity of the propositions of which we have episteme is something we are supposed to see (rather than something we prove by way of proving a proposition which tells us that something is necessary). No doubt this is supposed to happen because we see how the proposition follows deductively from first principles which are themselves necessary by dint of being definitions or the so-called common axioms.

But the central point to make concerning regress (2) above is that in his definition of episteme, Aristotle makes it clear that the cognitive relationship we are to have to the explanatory connection between the proposition that $\mathrm{P}$ and its explanation is not episteme. So it is not the case that to have episteme that $\mathrm{P}$ we have to have episteme that (P because $\mathrm{Q})$, and therefore episteme that ( $(\mathrm{P}$ because $\mathrm{Q})$ because $\mathrm{R})$ etc. Regress (2) is averted. ${ }^{19}$

Regress (1) is solved in the same way. Just as regress (2) was solved by Aristotle pointing to a different cognitive relationship (not episteme) that the knower must have towards

18 The propositions are 'necessary not in the sense that they are truths of the form " $A$ holds necessarily of every $B$ " but rather in the sense that they are propositions of the form " $A$ holds of every $B$ ", which are true inasmuch as $A$ necessarily holds of every $B$ ' (Barnes 1994, xxii).

${ }^{19}$ In Plato too, the verb used to describe the relationship between the knower and the explanation is not the verb غं $\pi \dot{i} \sigma \tau \alpha \sigma \theta \alpha$ : the knower is said to gain episteme that $\mathrm{P}$ by working out the explanation

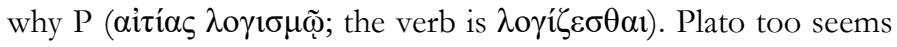
to have entertained the idea that knowing why $\mathrm{P}$ is not the same kind of knowledge as knowing that $\mathrm{P}$. 
the proposition 'P because Q', so Aristotle thinks that there is a different cognitive relationship (not episteme) that the knower must bear to the fundamental facts (first principles) in the relevant domain of knowledge. As we saw above, knowledge of a non-fundamental fact requires one to trace back the explanation right back to those fundamental facts. This can be seen straightaway from his description of the premisses of a demonstration as 'primary' and 'immediate' (71b21). To say a proposition is primary is (in part) to say that there is nothing prior to it, and say a proposition is 'immediate' is to say that it lacks an explanatory middle term (in other words, the word 'immediate' transposes into a syllogistic framework the notion of something having nothing prior to it). The explanatory structure of the world is thus stratified into facts which are primary and facts which derive from those primary facts. This metaphysical picture does not on its own solve regress (1), because, as Aristotle points out in Post $A n \mathrm{I} 3$, it may still be that our grasp of the explaining proposition or propositions for $\mathrm{P}$ needs to be episteme: i.e. it may be that the only available form of knowledge of a scientific proposition is explanation-involving knowledge (demonstrative knowledge) - in which case, there will be no episteme full stop, since it will be unavailable for the first principles of a science, and hence we will never have the requisite grasp of the first principles from which we will derive the theorems. He concludes that, if there is to be episteme at all, our grasp of those first principles cannot be the type of cognitive grasp of a proposition which involves knowing the explanation of that proposition. It must be a

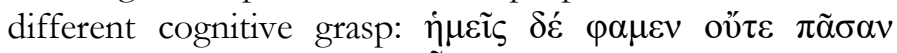

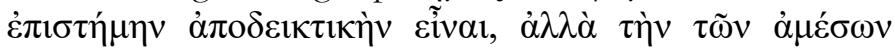

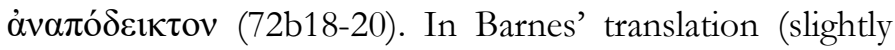
changed): 'we assert that not all understanding is demonstrative: rather, in the case of immediate items understanding is non-demonstrative'. Aristotle adds to this a

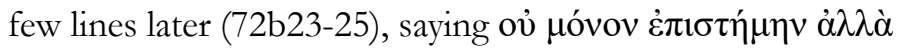




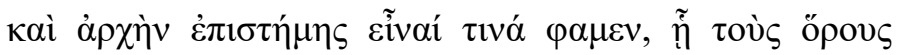
$\gamma v \omega \rho i \zeta o \mu \varepsilon v$ : 'we assert that there is not only understanding but also some principle of understanding by which we get to know the definitions'. This new kind of understanding is called both 'non-demonstrative', and a 'principle of (the other kind of) understanding. It is said to be the cognitive grasp we have of definitions, which is no surprise, since they are amongst the first principles of a science. It is this cognitive grasp of first principles, called 'non-demonstrative understanding' by Aristotle, which is the subject of this paper.

Let us recapitulate the main results of our discussion so far: episteme of a proposition is knowing why it is true; it is backward-looking, in the sense that to have episteme that $\mathrm{P}$ is to know the explanation of why $\mathrm{P}$, all the way back to first principles. To have episteme of a proposition $\mathrm{P}$ you have to see how the proposition that $\mathrm{P}$ fits into a network of other propositions, specifically, how the proposition that $\mathrm{P}$ is explained by a collection of other propositions grouped into a demonstration. In the case of Pythagoras' theorem, to have episteme of it is to see how it is explained by (or demonstrated by) the first principles of geometry. Perhaps many schoolchildren know the proposition, in some weak sense of 'know', but they can't prove or demonstrate it, and thereby explain why it is true, so that don't have episteme of it. Even showing them all the constituent propositions of the explanation of the theorem won't give them episteme; they have to see the explanatory connection between those propositions and the theorem. In addition to the kind of episteme which involves demonstrating of something there has to be non-demonstrative understanding, which is the kind of understanding appropriate for the first principles of a science. 


\section{\$3 NON-DEMONSTRATIVE UNDERSTANDING, OR NOUS: PRELIMINARY SKETCH}

Aristotle does not define episteme anapodeiktos in I 3, despite its importance in warding off regress (1). And even when he briefly returns to it in Post An I 33, he still does not define it. There, the context is that Aristotle is discussing the difference between episteme and doxa, and he observes that episteme is of necessary truths. However, he says, there are truths which are not necessary; what cognitive grasp is specifically of them?

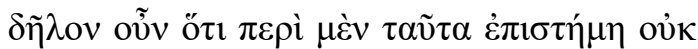

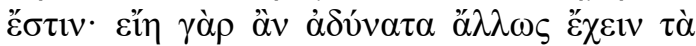

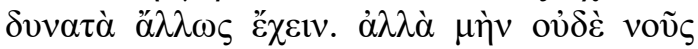

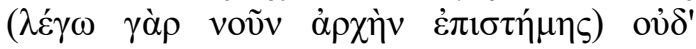

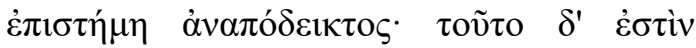

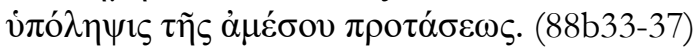

It is plain that understanding cannot be concerned with these items; for then what can be otherwise could not be otherwise. But then nor is it nous (I mean by nous a principle of understanding), i.e. not non-demonstrative understanding (this is grasp of an immediate proposition). [My translation]

Aristotle might appear here to dismiss two separate cognitive states as being the ones to do with non-necessary propositions: non-demonstrative understanding, and nous. But he identified non-demonstrative understanding and the principle of understanding back in Post An I 3 (see above), and here identifies the principle of understanding with nous,

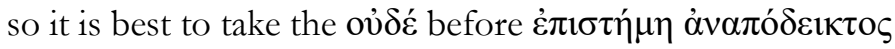


as epexegetic. ${ }^{20}$ Where before he had stressed that the principle of understanding is a cognitive state to do with definitions, here he says that it is of immediate propositions more generally.

But what is this cognitive state, nous? At first glance, it seems very unlikely that it is a species of episteme, if episteme is to be defined as Aristotle did in Post An I 2, since that definition required that for (this kind of) episteme that $\mathrm{P}$, one must grasp the explanation why $\mathrm{P}$ - but the propositions which nous grasps are ones which are immediate, i.e. they precisely lack an explanation.

Put the point another way: nous is our grasp of first principles. But episteme is backward-looking; it looks to the explanation of the proposition of which one is to have episteme. You can't have this kind of backward-looking knowledge of a first principle. A first principle has no explanation, hence our grasp of the first principles cannot be a grasp of their explanation all the way back to first principles, since there is no such explanation. (Pointing out that Aristotle argues that some principles in a given domain might be theorems in another domain - the doctrine of

20 LSJ already tells us that oủ $\delta \dot{\varepsilon}$ twice 'never means neither...nor...' (ov̉ $\delta \varepsilon$ II 2). And it should not be surprising that

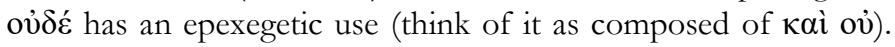
Barnes glosses oủ $\delta \varepsilon$ here as 'i.e. not' (Barnes 1994, 199), although

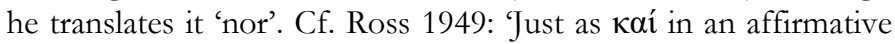
statement can have explicandi magis quam copulandi vis [...], so can

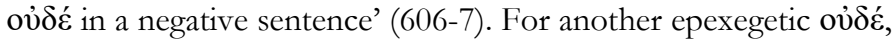
see Physics VI 5, 236a14, with Benjamin Morison, 'Aristotle on Primary Time in Physics 6', OS AP XLV, Winter 2013, 149-193, at 186. (Against the identification of nous and episteme anapodeiktos, see e.g. Orna Harari, Knowledge and Demonstration: Aristotle's Posterior Analytics (Dordrecht, 2004), 18.) 
subordination $^{21}$ - does not help here, since Aristotle could not argue that all first principles of a given domain are like that, on pain of regress again.)

Pretty clearly too, nous cannot be a matter of merely knowing the truth of a proposition which is in fact a first principle. Just as episteme of a theorem such as Pythagoras' theorem is a demanding thing, requiring the knower to grasp the explanation or proof of the theorem, by parity of reasoning, nous of a first principle should be demanding too. In fact, just as episteme of a theorem demands the knower to know a truth as a theorem, ${ }^{22}$ so too nous of a first principle should demand the knower to know a truth as a firstprinciple. ${ }^{23}$ Especially in natural science, many theorems are very easy to

${ }^{21}$ For this formulation of the doctrine, see Michael Frede, 'An Anti-Aristotelian Point of Method', in B. Morison and K. Ierodiakonou (eds.), Episteme etc.: Essays in Honour of Jonathan Barnes (Oxford, 2011), 115-137: the relation of subordination is 'when one science draws some of its principles from the theorems of another science' (118).

22 For a formulation of episteme along these lines, see Jim Hankinson, 'Avant nous le deluge: Aristotle's notion of intellectual grasp', in B. Morison and K. Ierodiakonou (eds.), Episteme etc.: Essays in Honour of Jonathan Barnes (Oxford, 2011), 30-59: 'Understanding of the derived truths consists purely and simply in seeing them as the derived truths that they are - recognizing their dependent position in the deductive hierarchy' (38).

${ }^{23}$ For a formulation of nous along these lines, see Lorenz, 2013, 301: it is 'the optimally authoritative grasp of those principles that one attains by identifying them as principles', with Richard McKirahan, Principles and Proofs (Princeton, 1992), at p. 243, and Aryeh Kosman, 'Understanding, Explanation and Insight' in E. N. Lee, A. P. D. Mourelatos, and R. M. Rorty (eds.), Exegesis and Argument: Studies in Greek Philosophy Presented to Gregory Vlastos (New York, 1973), 374-92, at p. 389.

Manuscrito - Rev. Int. Fil. Campinas, v. 42, n. 4, pp. 1-43, Oct-Dec. 2019. 
know (in an undemanding sense of the word). Aristotle himself acknowledges this when he talks of natural scientists starting their researches with things which are 'clear to us', ${ }^{24}$ meaning truths which are easily available to perception, such as 'trees blossom in spring', 'trees shed their leaves in the autumn', or 'the sun is eclipsed'. Many people know the truth of these, by experience. Far fewer people have episteme of them. For two things would be demanded of them: that they know these propositions to be necessary, and they can derive them from their appropriate first principles. If they can meet these two conditions, then they know those truths as theorems. But most of us are not in a position to prove such facts from the first principles of the appropriate branch of natural science, let alone see that these truths are necessary features of the world (this second condition is particularly demanding since there are so many exceptions we see around us; perception alone might tell us that most humans have two legs, but it won't tell us that all humans are biped, i.e. that it is a theorem of natural science, starting from first principles, that humans have two legs). To put it another way, Aristotle thinks that whereas many of us might know these everyday facts, as any moderately observant human would, most of us do not know that these facts are necessary or why they are true; knowing the necessity of these facts and knowing why they are true is a cognitive achievement that would require study, instruction, and research, possibly taking many years.

Similarly, many people merely know the truth of propositions which are in fact first principles, such as the fact that triangles have sides which are three straight lines, or that humans are rational creatures. But by parity of reasoning, we would expect far fewer people to have nous of those facts. (Remember that nous in these contexts is not some faculty of cognition which everyone has, but rather the excellence or

24 The classic text for this is Physics I 1, esp. 184a16-18.

Manuscrito - Rev. Int. Fil. Campinas, v. 42, n. 4, pp. 1-43, Oct-Dec. 2019. 
refinement of our ordinary capacities, just like episteme. ${ }^{25}$ ) But then what is this more demanding notion of knowing a fact such as 'triangles are plane figures whose sides are three straight lines' as a principle? What kind of knowledge could one have of that fact that would require study, instruction, and research, possibly over the course of many years? 26 If we are to settle the question of what it takes to know a proposition as a first principle, we have to get clear about what a first principle is. A first principle of a science has three features:

(i) There is no truth in the science which explains them (they are 'immediate', 71b21);

25 Of course, this aspect of nous is particularly emphasised in Nicomachean Ethics VI 6, where it is classed alongside the other intellectual virtues. For more on NE VI 6 and its remarks about nous, see Hankinson 2011, 39-41.

${ }^{26}$ I am here accepting, without argument, the thesis of David Bronstein that Posterior Analytics II 19 does not tell us the complete story about what is necessary for the acquisition of nous - the grasp of first principles as first principles - but only the preliminary story of how we obtain mere knowledge of those truths which are in fact first principles, or, as he puts it, 'how we acquire the preliminary accounts necessary for definitional enquiry' (Bronstein 2016, 229). Induction, perception, and memory tell me that triangles are plane figures whose sides are three straight lines (this is as far as the account of II 19 takes us); much more reflection and study is needed before I have a grasp of that proposition as a first principle in geometry. For the idea that nous must take many years to acquire, see again Lorenz, 'Understanding': acquiring nous of propositions is a matter of 'working out what roles they play in the explanations that pertain to the domain in question, in a painstaking process of organizing relevant facts and reasoning about them' (301). My interpretation of nous accords exactly with Lorenz's, as will become clear in the remainder of this paper.

Manuscrito - Rev. Int. Fil. Campinas, v. 42, n. 4, pp. 1-43, Oct-Dec. 2019. 
(ii) They explain other truths in the science (71b22);

(iii) They are necessary (71b12).

Features (i) and (ii) say something about the 'explanatory profile' of a first principle; feature (iii) says something about its modal status. Aristotle insists that the premisses of a demonstration be 'immediate', which is another way of phrasing feature (i), and that they are prior to (in the sense of explanatory of) the conclusion of the demonstration, which is another way of phrasing feature (ii). Feature (iii) is a commitment Aristotle has concerning the truths of science quite generally. We have a tendency to combine features (i) and (ii) into one metaphor: the first principles of a science are the foundations of the science. Foundations have nothing below them, but (crucially) they have something above them, on pain of not being foundations of something. ${ }^{27}$ So there seem to be three things that should be demanded of the person who is to have nous of the fact that P. They must know:

(i) There is nothing that explains why $\mathrm{P}$ (i.e. the proposition that $\mathrm{P}$ is an immediate proposition);

${ }^{27}$ It is tempting to think that Aristotle is trying to roll these two features into one when he says that demonstrations are from $\pi \rho \omega ́ \tau \omega \nu$ (71b21): 'primary' or 'first' things. (If you are first in a race, no one is ahead of you, and if there are others in the race, they are behind you.) Aristotle famously gives six conditions on the premisses of a demonstration: they must be true and first and immediate and more familiar than and prior to and explanatory of the conclusion. The third (immediacy) expresses what I have just called feature (i); the fourth, fifth, and sixth, all of which are relational, express feature (ii). Perhaps 'and' after 'first' is epexegetic; the next four conditions cash out what 'first' means here. 
(ii) The proposition that $\mathrm{P}$ explains the truth of other propositions;

(iii) It is necessary that $\mathrm{P}$.

These three conditions are modelled on the two conditions that Aristotle gives for episteme. Those two conditions were that we had to know the explanation for why $\mathrm{P}$ and know that it is necessary that $\mathrm{P}$, where the first of these could be summarised by saying that we have to know the explanatory profile or status of the proposition (we have to know, in particular, that it is a derived proposition). Similarly, the first two of the three conditions of our proposed definition of nous could be summarised by saying that we have to know the explanatory profile or status of the relevant proposition of which we have nous (we must know, in particular, that it is an underived proposition, used to derive others).

\section{\$4 IS NOUS A KIND OF EPISTEME, AS DEFINED IN I 2?}

There is an immediate objection to be made to this sketch of what nous is. The definition of nous just given fails to make nous a species of episteme as defined in I 2. The reason for this is that the definition of episteme speaks of episteme that $\mathrm{P}$ as consisting in knowing the explanation of why $\mathrm{P}$, whereas my two conditions for having nous of the proposition that $\mathrm{P}$ do not mention anything about knowing the explanation of why $\mathrm{P}$ (because, I have argued, the propositions of which one has nous lack an explanation). David Bronstein has rejected this proposed interpretation of what nous is. He argues that nous is in fact a species of episteme as defined in Post An I 2.28 At first glance, this looks to be impossible, since episteme of a proposition was there defined as knowing the explanation of that proposition, and the propositions which one has nous of

${ }^{28}$ Bronstein 2016, 51-57.

Manuscrito - Rev. Int. Fil. Campinas, v. 42, n. 4, pp. 1-43, Oct-Dec. 2019. 
are propositions which are immediate, i.e. which lack an explanation. But Bronstein has an answer to this. Struck by the thought that in seemingly calling nous a type of episteme, namely episteme which is non-demonstrative, Aristotle gives us to believe that it should fall under the definition of episteme as offered in I 2,29 Bronstein proposes to find explanations for the propositions which are the domain of nous - or rather, strictly speaking, he proposes to find explanatory structure within those propositions.

The trick Bronstein pulls is to pay careful attention to that definition of episteme in I 2. Aristotle said that when we have

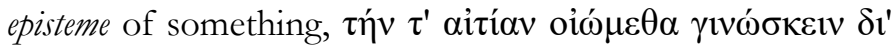

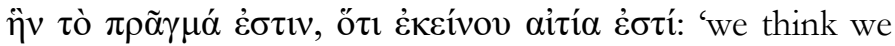
know of the explanation because of which the object holds that it is its explanation' (71b10-11). Bronstein points out that the word $\pi \rho \tilde{\alpha} \gamma \mu \alpha$ is ambiguous in Greek. Normally in this text it is taken to refer to propositions or states of affairs or something like that: things with propositional structure. But, argues Bronstein, it could also refer to objects, more simply. So maybe, suggests Bronstein, we should take the word $\pi \rho \tilde{\alpha} \gamma \mu \alpha$ to be referring to both types of thing in this definition: entities such as facts and entities such as objects. When it comes to facts, to have episteme of them we need to know their explanations, i.e. other facts. When it comes to objects, to have episteme of them we need to know their explanations. But what could it mean to know the explanation or cause of an object? Answer, according to Bronstein: it is to know its essence or definition. ${ }^{30}$

To take our example of a triangle, the essence of a triangle is to be a plane figure whose sides are three straight lines. So to have non-demonstrative episteme of triangles is to know

29 Op cit, 53.

${ }^{30}$ Op cit, 55. 
that the fact that something is a plane figure whose sides are three straight lines is what explains why that thing is the thing that it is, namely a triangle. ${ }^{31}$ Hence, there is episteme to be had of triangles which would manifest in one's grasp of the definition of a triangle. And this intellectual grasp of a definition, according to Bronstein, is episteme anapodeiktos, or nous of that definition. What would such knowledge consist in? It would consist in knowing that the predicate plane figure whose sides are three straight lines belongs to the subject triangle in virtue of nothing else - i.e. it would consist in knowing that this proposition is immediate. Contrast another proposition about triangles (Aristotle's favourite theorem about triangles), that triangles have angles adding up to two right angles. In this proposition, it is not the case that the predicate belongs to the subject in virtue of no middle term: many middle terms are required for the proof that triangles have this feature. Understanding that proposition is therefore a matter of knowing the relevant middle terms (i.e. knowing the relevant demonstration). By contrast, understanding that triangles are plane figures whose side are

31 With this, compare Lorenz 2013, 293: 'Now, there is room for the idea of a form of understanding that pertains to indemonstrable propositions which constitute principles of a science', because 'such propositions are self-explanatory'. The example Lorenz gives is the definition (or partial definition) 'animals are capable of perceiving'; contra Bronstein, Lorenz claims that Aristotle thinks of something's being an animal as explaining why it is capable of perceiving and not the other way round. But in any case, Lorenz (ibid) remarks that 'Aristotle seems to think that this is a marginal, non-standard case of an explanation', since Aristotle affirms in II 19 that episteme involves an account or explanation, and so there is no episteme of first principles (100b1011); Lorenz takes Aristotle's inference in that text to show that whatever kind of explanatory link there is between subject and predicate in a first principle, it is not one which is straightforwardly an account or explanation. 
three straight lines does not require the grasp of any middle term.

Transposed into the framework of this paper, Bronstein's proposal about what it would take to have nondemonstrative understanding of an immediate proposition of a science is that one would have to know the proposition as an immediate one. And of course, since Bronstein thinks non-demonstrative understanding is a special case of understanding, one must also know the proposition as necessary. So effectively, Bronstein wants to define nondemonstrative understanding as consisting only of conditions (i) and (iii) from my list above. According to him, therefore, it is not constitutive of understanding a first principle that one knows it as a proposition which explains other propositions: 'baving noetic knowledge that $\mathrm{E}$ [an essence] is the cause and essence of $\mathrm{S}$ [a subject] does not consist in knowing that $\mathrm{P}$ [a demonstrable attribute] belongs to $S$ because of E' (9; his emphasis, my clarificatory additions). On Bronstein's account, it is no part of having non-demonstrative knowledge of a definition of something that you know that it plays a foundational role in the derivation of other propositions about that thing, i.e. that the definition can function as a premiss in demonstrations. All you need to do is to know that the proposition is necessary and immediate. ${ }^{32}$

Bronstein's interpretation, if it is viable, would have the great virtue of bringing both non-demonstrative understanding and demonstrative understanding under the umbrella of the definition of episteme in I 2. But I want to give a few reasons for thinking that despite this virtue, the

\footnotetext{
32 Bronstein does acknowledge that in coming to know that a given definition is immediate, one will have to see how it explains other propositions in the science, but he is emphatic about the fact that this should not be part of the definition of nous (Bronstein 2016, 9). This paper aims to show that it should.
}

Manuscrito - Rev. Int. Fil. Campinas, v. 42, n. 4, pp. 1-43, Oct-Dec. 2019. 
interpretation suffers from a number of problems which on balance make it worth exploring a different interpretation.

First of all, there is a question about whether Aristotle's definition of episteme can support the dual reading that Bronstein wants. Bronstein is surely right that pragma is a word which can apply to propositions (or facts, such as the fact that triangles have angles adding up to two right angles) and also to things (or items, such as triangles). Our definition runs as follows: "We think we understand something simpliciter [...] when we think we know of the explanation because of which the object [pragma] holds that it is its explanation, and also [when we think we know] that it is not possible for it to be otherwise'. The word I have translated 'holds' is the verb $\dot{\varepsilon} \sigma \tau i$. In the case of a fact holding, the verb must mean 'is true' or something like that. In the case of a thing such as a triangle, the verb must mean 'is the very thing it is' (Bronstein, 55). So for Bronstein's interpretation to work, not only must the reference of the word pragma shift in order to generate the two types of episteme, so must the meaning of the verb $\dot{\varepsilon} \sigma \tau i$. This objection is not decisive; maybe there is a generic enough meaning for $\dot{\varepsilon} \sigma \tau i$ that we can get by ('have being', perhaps). But since Aristotle goes to great trouble to distinguish between the different uses of the verb غ̇ $\sigma \tau$ í elsewhere in the Posterior Analytics (e.g. in II 1), it is surprising that he did not say more about his exploitation of two different uses of the verb here.

Second, on Bronstein's account, episteme anapodeiktos will not actually end up being of the immediate propositions which are the first principles of the science. The objects of this knowledge will in fact be the items defined in the definitions (the definienda). The thing we will understand is the object being defined, in virtue of knowing its explanation, which is the clause defining it (the definiens). But what we wanted from Aristotle is an account of what the appropriate type of knowledge is of immediate first principles, the items which are the premisses of demonstrations. Even if episteme 
anapodeiktos applies to items such as triangles, what we wanted to know is what the knowledge is that we have of the propositions which are first principles. The argument in I 3 generated an infinite regress which was to be solved by positing a new kind of knowledge of the premisses of a demonstration, a new kind of knowledge which is not demonstrative understanding. Aristotle, on Bronstein's interpretation, is actually silent on the kind of knowledge appropriate for immediate propositions, and only tells us about the knowledge we have of pragmata.

Third, not every first principle is a definition. Aristotle tells us in the Posterior Analytics that immediate propositions come in two types: those that need not be grasped 'by anyone who is to learn anything', and those that do (72a15-16). The sorts of immediate proposition that need to be grasped by anyone who is to learn anything at all are the so-called 'axioms' (72a17), also called 'common axioms' or 'common principles': 33 these are principles common to several sciences (hence why they have to be grasped by anyone who is involved in scientific enquiry), in contrast with definitions such as that of a triangle, which will be found only in a science which deals with triangles (geometry). An example of what Aristotle means by 'axiom' is the proposition 'equals taken from equals leave equals' (Post $A n$ I 10, 76a41), which is also the third of Euclid's 'common notions' (the word 'common' is presumably there to indicate, as for Aristotle, that the 'notion' is to be found in other sciences, not just geometry). Since Aristotle explicitly calls this proposition 'immediate' (72a14), our account of nous, which was also glossed as grasp of necessary immediate propositions (Post An I 33, 88b37), had better apply to it as well. Yet it is totally unclear how to run Bronstein's analysis of Aristotle's definition of episteme, with pragma in its meaning of 'object', so as to apply to such a proposition. After all, such a proposition is not in subject-

33 See Barnes 1994, 99.

Manuscrito - Rev. Int. Fil. Campinas, v. 42, n. 4, pp. 1-43, Oct-Dec. 2019. 
predicate format, with the predicate giving the definition or essence of the subject. The proposition does not really talk about an object as such at all, and certainly cannot be taken as a definition of 'equals', since there are two other 'common notions' concerning equals that need to be included amongst the common axioms, namely the first of Euclid's common notions (two things equal to a third are equal to one another') and the second ('equals added to equals produce equals') - and surely one would not want to say that each of the three was a definition of 'equals'. In other words, we need to have an account of non-demonstrative understanding that is fit for accounting for our nondemonstrative understanding of both definitions and common axioms, but Bronstein's ingenious reworking of the definition of episteme in I 2 doesn't appear to provide such an account when it comes to the common axioms.

Fourth, eliminating from the definition of nous any mention of the fact that the propositions which are the objects of nous are propositions which explain things risks making nous too easy to acquire. Perhaps, for instance, I look at a definition of a geometrical object - an equilateral triangle - and realize that it will not be a proposition which is provable within geometry. I will meet condition (i): I will know that it is an immediate proposition. But suppose I think that such objects are explanatorily useless within geometry - they just simply 'sit there', as islands within the explanatory field, without doing any explanatory work. Then it seems as if I would still have nous of equilateral triangles, according to Bronstein's account. Yet surely I have missed something about equilateral triangles. I have failed to see the enormous importance they play in the science. Seeing the explanatory use to which such a definition can be put seems to me part and parcel of the geometer's expertise, and part and parcel of her grasp of that proposition in particular. (For more on this example, see below.) 
Thus, we want a definition of non-demonstrative episteme which will show how that cognitive grasp is of propositions (and not objects), and how it is of first principles quite generally (and not just definitions), and it will ideally advert to the explanatory role of first principles.

\section{\$5 THE DEFINITION OF NOUS}

My main account is now in place for what nous is. You have nous of the proposition that $\mathrm{P}$ just in case:

(i) You know that there is nothing that explains why $\mathrm{P}$ (i.e. you know that the proposition that $\mathrm{P}$ is an immediate proposition);

(ii) You know how to use the proposition that $\mathrm{P}$ to explain the truth of other propositions;

(iii) You know that it is necessary that $\mathrm{P}$.

As with the definition of episteme, the conditions need to be formulated using the verb 'to know' in a different sense than the sense of the verb implicit in the noun nous, namely noein. I propose to use the verb in whatever way it was that Aristotle used the verb in his definition of episteme. To have episteme that $\mathrm{P}$ is to know that something explains why $\mathrm{P}$, namely the proposition that Q; to have nous of something is (in part) to know that there is nothing that explains why P. The missing part of having nous of the proposition that $\mathrm{P}$ is to know how the proposition that $\mathrm{P}$ enters into the explanation of theorems.

To illustrate the idea, take a classic proposition that an expert geometer will have nous of:

(T) Triangles are plane figures whose sides are three straight lines. 
This is the definition of a triangle, and as such will be one of the principles of geometry (and indeed there it is, in Euclid's Elements book I, as part of definition 19). To have nous of $(\mathrm{T})$ is:

(i) To know that there is no other proposition in geometry that will serve to explain why triangles are plane figures whose sides are three straight lines;

(ii) To know how to deploy the proposition that triangles are plane figures whose sides are three straight lines in proofs about triangles (and other things) in geometry;

(iii) To know that it is necessary that triangles are plane figures whose sides are three straight lines.

It should be clear that this is a highly demanding kind of knowledge. No layman knows these three things about (T). Anyone can know the truth of (T): it is, after all, evidently true. Anyone can know, in other words, that $(\mathrm{T})$ is true. What is hard is to appreciate its place within the science: that it is an unexplained truth (condition (i)), which can serve as material for explanations for other truths in the science (condition (ii)). Just as it is relatively easy to know that Pythagoras' theorem is true (most of us remember it from school), yet highly demanding to know why it is true, so it is relatively easy to know that $(\mathrm{T})$ is true, yet highly demanding to know that there is no proposition which explains why (T) is true, and that $(\mathrm{T})$ can serve as a basis for explaining why other truths in geometry hold.

But condition (ii) is problematic. For episteme, we could say that you have episteme of a proposition when you know of the explanation of why that proposition is true that it is the explanation of why the proposition is true. It is 
determinate what that explanation is, ${ }^{34}$ and it will take the form of a (possibly complex) demonstration. But take the second condition for having nous of the proposition that P: you must know how the proposition that $\mathrm{P}$ explains the truth of other propositions. Which propositions? Which propositions must you know are explained by the proposition that $\mathrm{P}$, such that when you know how they can be so derived, you have nous of the proposition that P? This is a vexing question, and there seem to be three options, none of them attractive:

(1)We need to know of at least one theorem how to derive it from the proposition that $\mathrm{P}$, and then we have nous that $\mathrm{P}$.

This makes nous too easy to acquire. Someone who has mastered Euclid Elements I 1 (the construction of the equilateral triangle) would then count as having nous of all the first principles which are utilised in the course of that proof.

(2)We need to know of some privileged group of theorems how to derive them using the proposition that $\mathrm{P}$.

This proposal suffers from the problem that it is extremely difficult to say which theorems are privileged such that it is mastery of their derivation that confers nous of the first principles involved.

(3)We need to know of all theorems derivable from the proposition that $\mathrm{P}$ how to derive them from the proposition that $\mathrm{P}$.

\footnotetext{
34 For better or worse, Aristotle takes the view that explanations are unique (on this, see for instance Angioni 2016, 146): there is no suggestion in Aristotle that there are legitimate alternative axiomatisations (and hence derivations) for a given science.
} 
At this sight, this looks to be impossibly demanding. Especially in a field such as geometry, how could one possibly survey all the theorems? Surely there is an infinity of them? However, there may be an Aristotelian answer to this. Aristotle assumes that science will be formulated in his syllogistic. (This is one of the reasons why he is happy to use the word 'immediate' - 'lacking an explanatory middle term' - when talking about the first principles of a science: he assumes that the science will be couched in his dyadic term logic.) If a science is formulated in Aristotelian syllogistic, then if there are $\mathrm{n}$ first principles, there will be precisely $1 / 2 n(n-1)$ theorems. ${ }^{35}$ So assuming there are a finite number of principles, there will be a finite number of theorems to survey. Perhaps one could do such a thing? Perhaps - but such a view would be unattractive, philosophically speaking. For then it would be impossible ever to use your nous of the first principles to obtain episteme of a fresh proposition. And certainly, Aristotle sometimes talks as though this is what happens: one can use one's grasp of principles (a grasp which he claims is firmer than our grasp of theorems ${ }^{36}$ ) to obtain knowledge of the theorems.

Thus we want an interpretation of clause (ii) which would permit us to gain nous of a proposition without having to go through all the possible derivations from it in a science (as option 3 demands), but we also want an account which isn't too vague (like option 2) or implausibly weak (like option 1).

Here is my suggestion. Don't phrase clause (ii) as 'you must know of some propositions how the proposition that $P$ enters into an explanation of them'. Rather, just say: 'you

\footnotetext{
35 See Barnes 1969, p. 157 of the reprint.

36 When you go through a demonstrative syllogism, if it is to confer on you episteme of its conclusion, you must already know the primary propositions and know them better than you know the conclusion (I 2, 72a25-b4).
} 
must know how to use the proposition that $\mathrm{P}$ to demonstrate theorems'. It is a bad question now to ask: which theorems? When someone says that they know how to drive a car, the question 'which car?' is a curious question. The person is announcing that they have a general kind of knowledge. They are certainly not claiming to be able to drive every car: there are Formula One cars, which are very hard to drive (just as there are very hard theorems to prove). Nor is it just one car, or even a special group of cars that they claim to be able to drive. Simply, the person knows what's required to drive a car (and they know it through practical experience). What we want is an understanding of condition (ii) which imputes to the person with nous this kind of knowledge, how to use the proposition in the derivation of theorems, knowledge that they have gained through the practical experience of using the principle to derive theorems.

One way to think about the claim that someone with nous of the proposition that $\mathrm{P}$ knows how to derive theorems from it is to hear it as the claim that the person with nous of the proposition knows the different ways to use it in derivations. ${ }^{37} \mathrm{I}$ don't think it is a stretch to think that there is a finite number of ways in which propositions feature in proofs. One way to approach the issue is to think about definitions in particular. Definitions are of the form ' $\mathrm{X}$ is $\mathrm{Y}$ ', where $\mathrm{Y}$ and $\mathrm{X}$ have the same extension, and $\mathrm{Y}$ says what it is for something to be $\mathrm{X}$. Thus, definitions have a left-right and a right-left direction. The definition licenses you to derive, from the fact that something is $\mathrm{X}$, that it is $\mathrm{Y}$ (left-

\footnotetext{
37 Plausibly, it attributes to the person knowledge of all the ways to derive theorems with it, as opposed to the claim that someone knows how to swim: that seems to attribute to them only knowledge of some way of swimming, not necessarily all the ways. For discussion of this distinction (known as the distinction between 'mention-some' and 'mention-all' readings), see Jason Stanley, Know How (Oxford, 2011), \5.2.
} 
right direction), and from the fact that something is $\mathrm{Y}$, that it is X (right-left direction). (You could think of the left-right direction as being the 'elimination' of the defined term $\mathrm{X}$, and the right-left direction as being the introduction of the defined term X.) Both directions are important for proofs. Coincidentally, the first two proofs of Euclid's Elements Book I show just how definitions can be used in these two ways. In proposition 1 (for the construction of the equilateral triangle), a construction is performed and then it is observed that the three lines drawn together make an equilateral triangle. Now, that inference (right at the end of the proof) is a case of the right-left direction of the definition of equilateral triangle (which, putting together definitions 19 and 20 , is 'an equilateral triangle is a figure contained by three equal straight lines'). At the end of the construction, we have shown that we have three different straight lines of equal length, each pair of which share an end point, and therefore that they form a figure contained by three equal straight lines: from that we can conclude that the constructed figure is an equilateral triangle. On the other hand, in proposition 2 , after proposition 1 is invoked to construct an equilateral triangle, and two of the sides of that triangle have been extended outwards to the same length (through a variety of other constructions), Euclid reasons that since the figure is an equilateral triangle, the two sides are the same length, and hence the remainders of the two equally produced lines must also be the same length. Here, Euclid uses the left-right direction of the definition: because the figure is an equilateral triangle, its sides must be the same length. So already, by just looking at the example of Euclid's Elements, we can begin to get an idea of how the definitions of a science might be used in different ways, and how the expert will have to master those ways. Something similar will have to be said about the common axioms too. The expert knows how to deploy them in proofs, knowing when to apply them, which ones are 
likely to be called upon in probing a proposition of suchand-such a type, etc.

\section{\$6 A FEW REMAINING OBJECTIONS}

(1) Nous comes together with episteme

The account I have given so far of nous makes it a demanding cognitive state to be in with respect to a proposition. It is acquired by seeing that no other proposition in the domain will explain it (i.e. that it is immediate), and through repeated testing out of the explanatory potential of a proposition. One feature that may seem puzzling about this account is the order of acquisition of the various cognitive states: doesn't my account suggest that you first get episteme of the conclusions of demonstrations, and that only then, after a while, do you get nous of their premisses? If so, this goes against Aristotle's picture that nous is prior to episteme, insofar as it is a principle of episteme. If nous is acquired through conducting derivations of theorems before you have nous, what was going on during those derivations? Were you demonstrating? Did you have episteme of the conclusions you were deriving? Does episteme of a conclusion come before nous of its premisses, contra what Aristotle seems to say? The answers to the last three questions are: no, no, and no. There is a period when the scientist is coming to see the explanatory potential of the first principles, and coming to see how the conclusions derived from them are explained by them. During this phase, the scientist frames syllogisms which are demonstrations, but they are not themselves actually acquiring demonstrative knowledge of the conclusions when they are framing them. They are gradually building up a picture of the science. After a while, when the scientist finally sees how the first principles are fit for purpose, and able to 
explain things within the science, then they have nous of the first principles, and thereby episteme of the conclusions they have seen thus far. Nous (of the principles) and episteme (of the theorems) arrive together. ${ }^{38}$

This interpretation does not collapse nous and episteme. It does mean that to have episteme of a proposition, you must have nous of the principles for that proposition, and it does mean that if you have nous of a principle, you will have episteme of at least some things. This is only a problem if we think that it is possible to have nous of principles without having episteme of anything at all in the science, and there is precious little textual evidence for this. Aristotle does of course characterise nous as a principle of episteme, but that on its own need not mean that nous is always prior in time to episteme. The claim about nous being a principle of understanding can be explained as follows: first principles are principles of the theorems in a science, and hence the grasp we have of the principles will be a principle of the grasp we have of the theorems. That at least appears to be Aristotle's own explanation at the very end of the Posterior Analytics (II 19, 100b15-17): 'The principle [of understanding] will relate to the principle [of the science] as understanding as a whole is related to its object as a whole' (Barnes' translation with my additions). Just as the first principles are the basis for the theorems, so the grasp of the first principles is the basis for the grasp of the theorems. Other than that, there is a text in Posterior Analytics I 2, in which Aristotle says that to demonstrate one must 'not only

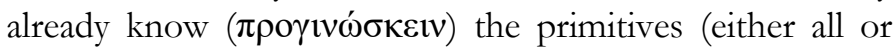
some of them), but also know them better' (72a27; Barnes' translation, adapted). But again, this text seems to me not to be decisive, by any means. ' $\pi \rho \gamma^{\prime} \boldsymbol{\prime} \omega ́ \sigma \kappa \varepsilon เ v '$ does not have to

38 With my account in this section, compare Breno Zuppolini, 'Comprehension, Demonstration, and Accuracy in Aristotle', JHP, forthcoming. 
mean 'know beforehand', but rather just mean that one's knowledge of the primitives in a demonstration has to be prior to (in the sense of being the principle of) one's knowledge of the conclusion of the demonstration.

Nonetheless, it is a feature of my account that a scientist can still continue to derive new theorems from the first principles of which they already have acquired nous. (Gödel, I suspect, had already mastered the axioms of logic and arithmetic when he derived the incompleteness theorems.) In those cases, nous will in fact be temporally prior to the episteme so gained, but this will not always be so.

(2) We have already discussed at length the definition that Aristotle gives of episteme in I 2. On my account, it turns out that this is a definition of the kind of episteme Aristotle calls demonstrative episteme. What then are we to make of the passage immediately following the definition, when Aristotle suggests that there will be another way of having episteme that he is going to clarify later: 'Whether there is also another type of understanding we shall say later: here we assert that we do know things through demonstration' (71b16-17)? On Bronstein's view, this means the following: 'whether there is another way of understanding, other than the way I am about to tell you about in the next few lines, vir: demonstrative knowledge, I shall tell you later.' The way he will tell us about later is nous, in chapter 3, which is (on Bronstein's account) another way of having the episteme defined in I 2. On my interpretation, it means the following: "whether there is another way of understanding things in addition to the way I have just told you about, vi\%: demonstrative knowledge, I shall tell you later.' The way he will tell us about later is nous, in chapter 3 , which is indeed (on my account) another way of understanding things separate from the one just defined in I 2, which was demonstrative knowledge. Linguistically, both 
interpretations are possible (it is purely a matter of whether 'another way' is taken to refer backwards or forwards).

However, my interpretation does posit a meaning for episteme which is broader than the one defined in I 2. That should not come as a surprise: after all, I don't want episteme apodeiktike and episteme anapodeiktos to be two species of the episteme defined in I 2; rather, I want the episteme defined in I 2 to be episteme apodeiktike, ${ }^{39}$ and that type of episteme, together with episteme anapodeiktos, to be two species of a wider notion of episteme. Of course, the drawback with my interpretation is that Aristotle never defines or elucidates that wider notion of episteme. But it's not hard to see how to characterise it. It is something like this: having episteme (in the broad sense) of a proposition is something like seeing its place in the explanatory network of propositions which constitute the science it belongs to. ${ }^{40} \mathrm{It}$ is something like the optimal grasp available for a necessary proposition, depending on what type of proposition it is, a first principle, or a theorem.

(3) What about the fact that theorems have explanatory profiles too?

Take Pythagoras' theorem. It can be used to derive other theorems. In fact, it is crucial for the unfolding of Euclid's Elements, notably for proving the construction of the mean proportional. Doesn't that mean that there is such a thing as appreciating the explanatory potential of a theorem? What is

\footnotetext{
39 This is a well-established interpretation: see for instance Gail Fine, 'Aristotle on Knowledge', Elenchos 14 (2010), 121-56, at 129 n.16 and 139 (together with other references in Bronstein 2016, 52 n.3, and Angioni 2016, 140-1).

40 See also Breno Zuppolini, 'Aristotle's Foundationalism', Dissertatio 44 (2016), 187-211, at 200.
} 
that cognitive grasp? Surely it is not nous of Pythagoras' theorem - nous is reserved for immediate propositions. And surely it is not episteme of Pythagoras' theorem - episteme is backward-looking towards the derivation of theorem from first-principles, not forward-looking to what can be derived from it. Since Aristotle does not hive off this special kind of cognitive grasp in the case of theorems, and add it into what it takes to have expert grasp of theorems, why think that he would hive it off in the case of first principles, and build it into what it takes to have expert grasp of them?

In a way, the objection is easy to answer. It is an indispensable part of mastering a first principle that you know how to use it in deriving other propositions - because it is in the nature of a first principle to be a principle of something. However, it is not an indispensable part of mastering a theorem that you know how to use it to derive other theorems - because it is not in the nature of a theorem to be a premiss for other theorems. Even if a proposition (such as Pythagoras' theorem) is a stepping-stone in a longer proof, it can be understood independently of that.

\section{\$7 CONCLUSIONS}

Thus, nous of a proposition such as a definition is not easy to come by. You don't have it just in virtue of knowing that a definitional statement is true. (The truth of such statements is, after all, typically rather easy to see.) It takes years of work to obtain nous of such a proposition. It will come by seeing its relation to the other propositions in the science, in particular, the different ways in which it is explanatorily involved with them. Consider, for instance, the fact that a layperson might well know that isosceles triangles have two sides that are equal. But they will also know that they have two angles which are equal. Only an expert geometer knows which one of these propositions is the proper definition of an 
isosceles triangle, because only an expert geometer can know which is the more appropriate proposition to feature in the explanatory basis of geometry. ${ }^{41}$ In its demandingness, nous is parallel to episteme. For there are many theorems of a science whose truth is very easy to see; this is particularly the case in natural science, where propositions such as 'trees blossom in spring and shed their leaves in autumn' are easily known by observation. But having episteme of them requires immersion in the science and hard work mastering their demonstration on the basis of the basic truths in natural science.

Nous and episteme thus combine jointly to exhaust the epistemic achievement of the expert scientist. My account of nous falls short of offering a fully worked-out account of what the different ways are in which a principle might feature in a proof. But that nous is something along the lines of what I have sketched, and that its epistemological profile could be made fully explicit, I am confident. ${ }^{42}$

${ }^{41}$ In Euclid, the equality of two of the sides is the definition (definition 20), and the equality of the angles at the base is derived as theorem I 5. For similar remarks, see Zuppolini, forthcoming.

${ }^{42}$ I am grateful to audiences in Oxford, Paris, Princeton, Porto Alegre, and Sao Paulo, and the audience at the Orange Beach Epistemology Workshop, Alabama. I am also grateful to David Bronstein, Solveig Gold, Daniel Kranzelbinder, and Hendrik Lorenz for detailed discussion. Breno Zuppolini and I were pleased to discover that we had independently come to similar views about nous, and I'm grateful to him and Lucas Angioni for their comments on this paper (and providing me with references to their work). While I was in the final stages of preparing this paper for publication, the news broke of Myles Burnyeat's death. I should like to dedicate the paper to his memory. His papers on the Posterior Analytics set a high standard for those of us who work in his shadow. 


\section{REFERENCES}

ANGIONI, L. 'Demonstração, Silogismo e Causalidade', in Lucas Angioni (ed.), Lógica e Ciência em Aristóteles (Campinas, 2014), 61-120

'Aristotle's Definition of Scientific Knowledge', in P. S. Hasper and K. Ierodiakonou (eds.), Logical Analysis and History of Philosophy 19: Ancient Epistemology (Münster, 2016), 140-66

BARnes, J. Aristotle: Posterior Analytics, second edition (Clarendon Aristotle Series; Oxford, 1994)

'Proof and the Syllogism', in E. Berti (ed.), Aristotle on Science: the Posterior Analytics (Padua, 1981), 17-59. Reprinted in his Proof, Knowledge, and Scepticism: Essays in Ancient Philosophy III (Oxford, 2014), 95-128. Page references to the reprint.

'Aristotle's Theory of Demonstration', Phronesis 14 (1969), 123-152. Reprinted in his Proof, Knowledge, and Scepticism: Essays in Ancient Philosophy III (Oxford, 2014), 129-57. Page references to the reprint.

BeERE, J. and Morison, B. 'A Mathematical Form of Knowing How: the Nature of Problems in Euclid's Geometry', unpublished ms.

BronsteIn, D. Aristotle on Knowledge and Learning: The Posterior Analytics (Oxford, 2016)

BURNYEAT, M. 'Aristotle on Understanding Knowledge', in E. Berti (ed.), Aristotle on Science: The Posterior Analytics (Padua, 1981), 97-139

'Episteme', in B. Morison and K. Ierodiakonou (eds.), Episteme etc:: Essays in Honour of Jonathan Barnes (Oxford, 2011), 3-29 
FINE, G. 'Aristotle on Knowledge', Elenchos 14 (2010), 12156

Frede, M. 'An Anti-Aristotelian Point of Method', in B. Morison and K. Ierodiakonou (eds.), Episteme etc.: Essays in Honour of Jonathan Barnes (Oxford, 2011), 115137

HANKINSON, J. 'Avant nous le deluge: Aristotle's notion of intellectual grasp', in B. Morison and K. Ierodiakonou (eds.), Episteme etc.: Essays in Honour of Jonathan Barnes (Oxford, 2011), 30-59

Harari, O. Knowledge and Demonstration: Aristotle's Posterior Analytics (Dordrecht, 2004)

Kosman, L. A. 'Understanding, Explanation and Insight' in E. N. Lee, A. P. D. Mourelatos, and R. M. Rorty (eds.), Exegesis and Argument: Studies in Greek Philosophy Presented to Gregory Vlastos (New York, 1973), 374-92

LorenZ, H. 'Understanding, Knowledge, and Enquiry in Aristotle', in F. Sheffield and J. Warren (eds.), Routledge Companion to Ancient Philosophy (London, 2013), 290303

MCKirahan, R. Principles and Proofs (Princeton, 1992)

Morison, B. 'Aristotle on Primary Time in Physics 6', OS AP XLV, Winter 2013, 149-193

'Practical Nous in the Nicomachean Ethics', OS AP LVII, Winter 2019, 219-47

Ross, W. D. Aristotle's Prior and Posterior Analytics: A Revised Text with Introduction and Commentary (Oxford, 1949)

Sharples, R. W. Plato: Meno (London, 1985)

STANLEY, J. Know How (Oxford, 2011) 
Zuppolini, B. 'Aristotle's Foundationalism', Dissertatio 44 (2016), 187-211

'Comprehension, Demonstration, and Accuracy in Aristotle', Journal of the History of Philosophy, forthcoming

$(\infty)$ EY

Manuscrito - Rev. Int. Fil. Campinas, v. 42, n. 4, pp. 1-43, Oct-Dec. 2019. 